Pulse

\section{Alternative remuneration}

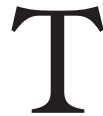
he nation's 59655 physicians are ever earning more of their daily bread through alternative forms of payment to fee-for-service, according to a new Canadian Institute for Health Information (CIHI) report.

Some $20.5 \%$ of the value of physicians' clinical payments in fiscal 2004-05, or roughly $\$ 2.65$ billion, was earned through alternative remuneration like emergency and on-call (alternative payments typically in rural areas), block funding (annual budgets negotiated for a group of physicians, usually in an academic medical center), sessional (hourly or daily payments, often for emergency department night shifts or specialized care like family health, psychiatric or cystic fibrosis clinics), salary and capitation (monthly allocations to physician groups for rostered clients) payments, CIHI states in its report, The Status of Alternative Payment Programs for Physicians, 2004-05 and Preliminary Information for 2005-06.

The $\$ 2.65$ billion constitutes a $9.8 \%$ increase over a 2003-04 tally of \$2.4I billion. Between 200I-2005, such alternative remuneration more than doubled, to \$2.65 billion from \$I.3 billion (Fig. I). That trend appears to be continuing as preliminary estimates for 2005-06 indicate that $\$ 2.98$ billion, or roughly a Io\% increase, issued through alternative payment plans.

The report also indicates that overall outlays for both fee-for-service payments to physicians, and alternative forms of remuneration, rose over the 5year period. But fee-for-service payments constituted a declining share of the overall physicians' pie. Fee-forservices outlays in 200 I were $\$ 8$.7I billion or $87 \%$ of the overall \$10.02 billion pool. By 2005, outlays had risen to \$I0.28 billion, or $79.5 \%$ of the overall $\$$ I2.93 billion pool.

The report generally indicates the use of alternative remuneration rose in all provinces between $200 \mathrm{I}$ and 2005 , albeit at varying rates. It rose in Newfoundland and Labrador (from $32.3 \%$ to $4 \mathrm{I} .2 \%$ ), PEI (from I8.I\% to

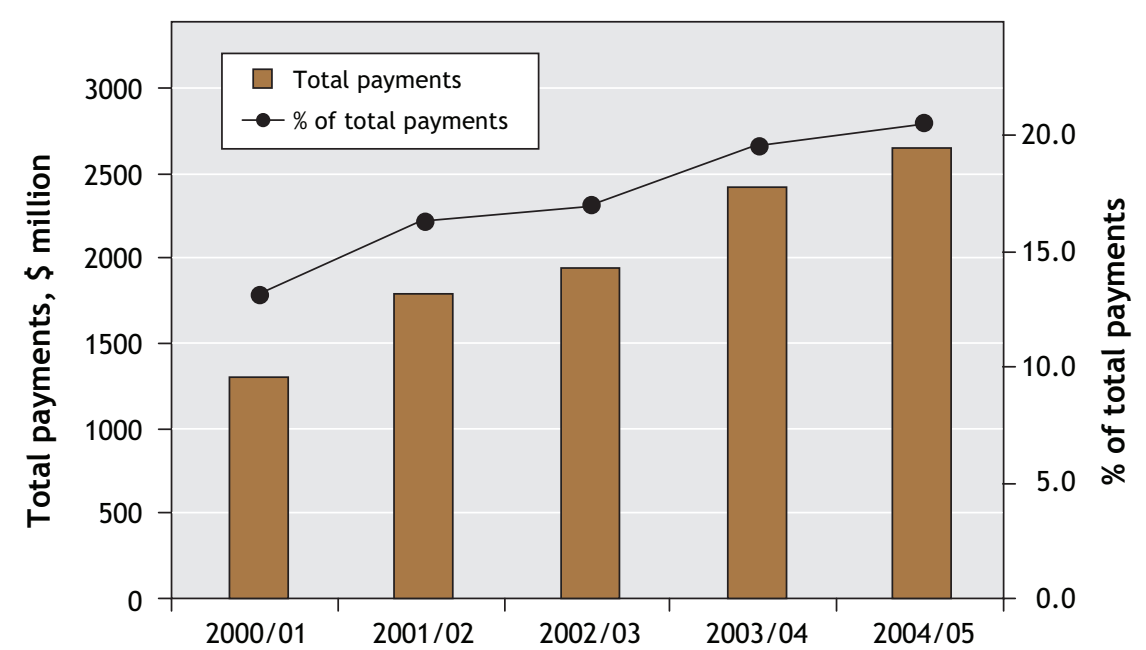

Fig. 1: Physicians' alternative (non-fee-for-service) clinical payments in Canada, 2000/01 to 2004/05. Source: Canadian Institute for Health Information.

33.I\%), Nova Scotia (from $27.9 \%$ to 4I. $5 \%$ ), New Brunswick (from $16.5 \%$ to $23.6 \%$ ), Quebec (from I9.I\% to $23.9 \%$ ), Ontario (from $8.5 \%$ to I6.8\%), Manitoba (from 27.I\% to $29.6 \%$ ), Saskatchewan (from $22.0 \%$ to $26.4 \%$ ), Alberta (from $2.8 \%$ to I0.8\%) and BC (from I $2.5 \%$ to I9.9\%).

CIHI Senior Analyst, Health Human Resources Jonathan Mitchell says the report does not attempt to identify and articulate factors that are influencing the trend towards greater use of alternative forms of remuneration.

Yet, factors that may be at play, particularly with respect to provincial variations, include the greater use of international medical graduates (IMGs) in some provinces compared with others. IMGs working on restricted licenses cannot be compensated through feefor-service. As a result, provinces that more frequently hire IMGS to work in rural and remote areas have little option but to use alternative forms of remuneration.

The report also indicates there are significant variations in the nature of alternative clinical payments used by provinces. Quebec, for example, spends \$327.4 million on a block funding program introduced in 1999 that remunerates specialists by providing them with a flat daily rate plus a percentage of fee-for-service rates for insured services. Quebec also provides far more sessional funding than any other province, issuing \$222 million for sessional payments to general practitioners in community health programs, family health clinics, geriatric care and psychiatric institutions, or for work in remote areas. Ontario, meanwhile, provides far more monies for emergency and on-call payments (\$I88.3 million) than any other province and is one of the few provinces to have forayed into capitation (\$48.2 million).

The report also says roughly $55 \%$ of all Canadian physicians now receive at least a portion of their clinical income through alternative funding payments, with significant variation between jurisdictions. About I0\% of physicians in Alberta and the Yukon received such payments, as compared to $75 \%$ in Manitoba and Nova Scotia, and 96. $\%$ in the Northwest Territories.

The number of physicians who rely on alternative funding to generate at least half of their clinical income also varies. About $25 \%$ of physicians in Quebec, Nova Scotia and New Brunswick, and about $12 \%$ of physicians in $\mathrm{BC}$ and Ontario, receive at least $50 \%$ of their clinical income through alternative modes of funding. Again, virtually all (96.8\%) physicians in the Northwest Territories fall in that category. Wayne Kondro, CMAJ

DOI:I0.I503/cmaj.070550 